\title{
Sustainable Case Study: University Of Pittsburgh Medical Center
}

\author{
Steve Clinton, Ph.D., Robert Morris University, USA \\ Gayle Marco, Ph.D., Robert Morris University, USA \\ Dean R. Manna, Ph.D., Robert Morris University, USA \\ Amanda Weir, (student), Robert Morris University, USA
}

\begin{abstract}
University of Pittsburgh Medical Center (UPMC) mission is to provide outstanding patient care and to shape tomorrow's health system through clinical innovation, biomedical, and health services research, and education. By operating their health system by this mission, UPMC is the leading health provider in Pittsburgh. Their vision is to create a new economic future for western Pennsylvania. They want to build a new perspective of the way people think about health care by creating new avenues in the health care field.
\end{abstract}

Keywords: Healthcare; Specialty Hospitals; Sustainable; Children's Hospital of Pittsburgh

\section{THE UPMC STORY}

$Q$ PMC has come a long way since its beginnings as a single psychiatric hospital in 1893. It is affiliated with the prestigious University of Pittsburgh, and as research and technology become more advanced so did the Medical Centers. From its humble beginnings in 1893, UPMC has transformed through the years. Below is a brief timeline of the history as described by UPMC:

- $\quad$ In 1893, the tertiary care hospital that was to become UPMC Presbyterian was founded.

- In 1973, a comprehensive reorganization of Western Psychiatric Institute and Clinic and the University of Pittsburgh's Department of Psychiatry, under the leadership of Dr. Thomas Detre and Jeffrey A. Romoff, began a new era of research-based medicine in Pittsburgh, and set the stage for UPMC's eventual mission of clinical care, research, and teaching.

- In 1986, three university-affiliated hospitals, Western Psychiatric Institute and Clinic, PresbyterianUniversity Hospital, and Eye \& Ear Hospital of Pittsburgh unified under an organization that would evolve into UPMC.

- In 1990, the name "University of Pittsburgh Medical Center," or UPMC, was adopted. UPMC continued to merge with community and specialty hospitals, creating the first truly integrated health care delivery system in the Pittsburgh region.

- In 1997, recognizing the efficiencies possible from complementing its provider network with a health insurance product, UPMC started what today is its Insurance Services Division.

- $\quad$ From 1893 until now, they have become an $\$ 8$ billion integrated global health enterprise dedicated to changing the face of health care and creating a new export economy for the Pittsburgh region.

- $\quad$ The revolution of this global health enterprise can be constituted by their focus on their core values. These values, as described by UPMC, include:

- Consider their people to be their greatest asset and seek to be responsive to the needs of individuals of all backgrounds.

- Strive for excellence in everything they do and believe that each member of the faculty and staff is responsible for the continuous improvement of quality in all aspects of the services provided.

- Committed to understanding and satisfying the expectations and requirements of customers.

- Strive to provide an environment that supports and encourages the active leadership and participation of physicians throughout the system and fosters collaboration among health care professionals across programs and service lines. 
- Support a culture that embraces change and encourages innovation. Pursue organizational integration in order to achieve the highest and best use of UPMC's collective resources.

- As the only academic medical center in western Pennsylvania, UPMC shares with local, state and national governments responsibility for health and safety of the community, including crisis intervention.

- As stewards of the community's resources, UPMC seeks to operate in an efficient and effective manner in order to maintain financial strength and carry out the organization's mission, as well as to contribute to the economic stability and growth of the region.

\section{SUSTAINABLE HEALTH CARE}

UPMC was the first health care system to be selected for the U.S. Environmental Protection Agency's (USEPA) Region 3 Sustainable Healthcare newsletter highlighting their environmental initiatives. This was in their January 2010 issue, and it talked about UPMC and their commitment to the community in regards to reducing their regional environmental impact. Another initiative UPMC has been noted for by the USEPA has been their new role in becoming a "green" healthcare system. UPMC recycles medical equipment and has removed mercury from their hospitals. They also educate new parents on harmful environmental issues and support research to further understand the connection between the environment and diseases.

UPMC states "sustainable health care" as:

- Health care administration, operations, and services that balance quality and performance with the practice of sustainability.

- $\quad$ Any health care service or process that conscientiously conserves resources and minimizes waste.

- A means of operating, which may require new or different products and processes that might not yet exist or exist, but are not currently used in the health care industry.

UPMC defines sustainability as the attempt to achieve outcomes that support prolonged human life and protect the environment without compromising resources of future generations.

\section{Sustainable Initiatives}

With support from the Heinz Endowments and other partners UPMC was able to make ground breaking sustainable initiatives. These green initiatives are as followed:

- In 2007, there was a creation of a \$5 million "green action fund" to support new environmental initiatives across the health system. Projects funded to date include installation of energy-efficient heating and cooling systems.

- $\quad$ Commitment to green construction and renovation. The new Children's Hospital of Pittsburgh of UPMC is one of the first LEED-certified children's hospitals in the nation, thanks to the use of recycled building materials, low-VOC paints and carpets, green roofing systems, water-efficient landscaping, water fixtures that reduce usage, and other environmental factors.

- $\quad$ UPMC's renovation of executive and administrative offices at the U.S. Steel Tower won LEED-Silver certification for energy conservation and environmental design. A new tower at UPMC PassavantMcCandless and the new UPMC East campus in Monroeville are also expected to be LEED-certified.

- Development of a first-of-its-kind energy management program for hospitals in collaboration with the U.S. Dept. Of Energy. UPMC serves on the steering committee of the DOE's Health Energy Alliance, a partnership with other national health care leaders to lower energy usage, cut costs, and reduce pollution in this energy-intensive industry.

- $\quad$ Establishment of the Pediatric Environmental Medicine Center at Children's Hospital of Pittsburgh of UPMC, with a five-year grant from the Heinz Endowments. UPMC recruited a nationally known asthma researcher to serve as the center's clinical director, while leading efforts to identify how environmental risk factors impact children with asthma in western Pennsylvania. 
- $\quad$ Since July 2007 a ban on smoking was in place at all health system facilities and grounds. To assist with the ban smoking-cessation assistance is offered free of charge to staff. The move reinforced UPMC's commitment to maintaining a healthy and safe environment for staff and patients.

- $\quad$ Purchase of renewable energy certificates from First Energy to offset 10 percent of UPMC's energy demand.

- $\quad$ Partnership with Duquesne Light to implement software that will put PCs into "sleep" mode at appropriate times and cut PC power usage by 50 percent.

- $\quad$ Donation of more than a quarter-million pounds of medical supplies over the past decade to Global Links, a local, not-for-profit organization that recovers surplus medical materials from U.S. hospitals and makes them available to hospitals serving underprivileged populations in developing countries. This helps the environment, as well as needy countries, by keeping materials out of landfills.

- $\quad$ Promotion of paper reduction through a centralized printing services contract with Xerox, adoption of electronic medical records, and paperless paycheck and retirement accounting systems. In addition, the health system now recycles more than 1 million pounds of paper annually and is expanding those efforts.

- $\quad$ Education of staff, patients, and communities on environmentally sustainable practices and environmental links to disease. Magee-Women's Hospital of UPMC, winner of the 2009 Partner for Change Award from Practice Green health, offers a class to families on environmental health concepts and, since 2005, has included environmental education in its childbirth and newborn classes. Magee also sponsored the Teresa Heinz Women's Environmental Health Conference in 2007 and 2008, attracting more than 2,000 attendees. Children's Hospital of Pittsburgh of UPMC provides a continuing medical education-accredited lecture series for residents, which focuses on environmental health issues.

- $\quad$ Replacement of all mercury-containing items found in patient care devices, lab thermometers, mercury switches, thermostats, and traditional fluorescent bulbs, at UPMC Presbyterian Shadyside and MageeWomen's Hospital of UPMC.

- Conversion of three Magee-Women's Hospital courtyards into herb, vegetable, and healing gardens. Designed by the Phipps Conservatory, the gardens will provide fresh ingredients to be used in the preparation of healthful meals for staff and patients.

\section{THE NEW CHILDREN'S HOSPITAL}

As stated above, the new Children's Hospital of Pittsburgh of UPMC is one of the first LEED-certified children's hospitals in the nation. Beyond the bricks, Children's Hospital has identified that they have implemented new operating policies and procedures regarding facility maintenance, housekeeping, food service, and waste management. Children's Hospital also enforces its green philosophy by working with clinicians, academicians, and community to conduct research on the subject of sustainability and its health effects on children. Listed below is a brief look at how Children's Hospital is environmentally friendly:

- $\quad$ Easy access to public transportation

- $\quad$ Availability of bike racks and showers

- $\quad$ Preferred parking for van pools

- $\quad$ Discounted parking for car pools

- Water efficient landscaping

- Use of building materials with recycled content (including recycled post-consumer structural steel)

- Use of local/regional construction material to reduce transportation issues

- Use of low VOC materials such as sealants, adhesives, paints, and carpets

- Installation of air filtration systems that increase indoor air quality.

- Installation of water fixtures that reduce water use

- $\quad$ Maximum use of daylight and views

Children's Hospital is also committed to environmental responsibility by:

- $\quad$ Employing a "green" education program for staff, patients, and visitors

- Installing a healing garden/rooftop gardens

(C) 2012 The Clute Institute http://www.cluteinstitute.com/ 
- $\quad$ Continued use of recycled content and local materials whenever possible.

\section{ENVIRONMENTAL INITIATIVES AT MAGEE-WOMEN'S HOSPITAL}

Along with Children's Hospital, Magee-Women's Hospital has eliminated virtually all mercury-containing equipment. From that initiative, Magee received the Making Medicine Mercury Free Award as well as the Partner Recognition Award from Hospitals for a Healthy Environment, two premier national distinctions of environmental achievement in health care. In 2009, Magee-Women's Hospital received the Partner for Change Award and the DEHP-Free Award from Practice Green health.

In acknowledgment of the education and outreach to health care professionals on topics of environmental health, Magee received the 2007 Children's Environmental Health Excellence Award from the USEPA Office of Children's Health Protection.

To make those awards possible Magee and every UPMC has been assigned a Green Team. This team is made up of a representative body of hospital staff. Together they set goals, review the actions that have been going on, and measures their green initiatives to all of the other UPMC's Green Teams.

\section{UPMC AND SUPPLY CHAIN}

UPMC is committed to an Environmentally Preferable Purchasing (EPP) process. This entails only purchasing products and services that are environmentally friendly and are considered to have a less harmful effect to the environment and human health when compared to other products. As long as "green" alternatives exist, they do not get in the way of patient care. UPMC is constantly reviewing supply opportunities without compromising its existing sourcing practices, contractual negotiations, or its mission to obtain optimal products/services and pricing. In accordance with the EPP, Supply Chain Management (SCM) is devoted to providing the choice to use and purchase environmentally and socially responsible materials and products. It is the responsibility of SCM in coincidence with all UPMC departments and stakeholders to promote the advancement and use of environmentally friendly products and services through the following activities:

- $\quad$ Reviewing contracts, bids and specifications for products and services to ensure that whenever possible and economical, they are amended to provide the option for the use of or purchase of green products and services.

- $\quad$ Promoting the purchasing of products from suppliers that have and demonstrate similar concerns about environmental sustainability and about the health of current and future generations.

- Working with the UPMC System-wide Green Team to identify new environmentally friendly products, services and process improvements/changes in industry standards that may impact the environment.

- $\quad$ Utilizing Life Cycle Analysis (LCA) to arrive at an informed sourcing decision when purchasing from suppliers that provide environmentally friendly products and services.

- $\quad$ Educating UPMC personnel delegated with purchasing authority on UPMC's EPP policy, processes and operating procedures.

- $\quad$ Making suppliers aware of UPMC's EPP policy.

One example of the EPP is demonstrated through UPMC's relationship with Global Links. Global Links is a nonprofit medical material aid organization that has its headquarters in Pittsburgh. They assist UPMC when it comes to the removal, recycling, and disposal of UPMC's surplus property.

\section{Award Winning Healthcare}

UPMC has been doing a lot of things right in the past few years. They have received numerous recognitions for their outstanding healthcare. They were ranked $13^{\text {th }}$ in U.S. News \& World Report's annual guide for one of "America's Best Hospitals". This report only includes 14 other hospitals nationwide that are considered to be the "best of the best". UPMC has now made this list for 11 year's. UPMC continues to reinvent itself to anticipate and prepare for the challenges facing academic and nonprofit medicine, both today and tomorrow. 


\section{AUTHOR INFORMATION}

Dr. Steven R. Clinton received his Ph.D. degree (Major: Marketing; Minor: Logistics) from Michigan State University in 1998. His research interests include international supply chain organization, customer service in logistics, logistics strategy, and selection processes involving international logistics service intermediaries. Steve is an Associate Professor of Marketing at Robert Morris University. He has published in Journal of Business Logistics, Transportation Journal, International Journal of Physical Distribution and Logistics Management, Journal of Production and Inventory Management, and International Marketing Review as well as numerous conference proceedings. E-mail: Clinton@rmu.edu

Dr. Gayle J. Marco received her Ph.D. degree from the University of Pittsburgh. (Major: Marketing Education and Vocational Education) Her research interests include various areas of consumer decision making, buyer behavior and the various areas of sustainability. She has consulted for numerous companies in the Pittsburgh area. The consulting areas include product repositioning, market development for new products, needs assessments, and market plan development. Professor Marco integrates "real" marketing projects for area businesses in her teaching at the undergraduate and graduate level. She has published in the Journal of Global Business, The Journal of American Academy of Business, American Journal of Business Education, and Journal of Business Case Studies as well as numerous conference proceedings. E-mail: marco@rmu.edu

Dr. Dean Manna has consulted and conducted training seminars for twenty-five years in the areas of Emotional Intelligence related to professional selling and management. Dr. Manna utilizes a pragmatic yet highly motivational and entertaining approach in his classroom instruction and seminars, while transmitting valuable information. He has published a complete instructional manual on Client Centered Selling for use in the classroom and corporate training. His teaching specialty is in the area of Professional Selling and Emotional Intelligence, both at the undergraduate and graduate level. Dr. Manna's primary research interest is on Emotional Intelligence and its effects on productivity and morale in the public and private sector. He has made several presentations at various national and international conferences. He also has over twenty publications in various academic journals. Dr. Manna was a past president of the Pittsburgh Chapter of the American Marketing Association. He holds his undergraduate degree in Business from Gannon University, an MBA from the University of Cincinnati, and his Ph.D. from the University of Pittsburgh. He is a University Professor of Marketing and Department Head of the Marketing Department in the School of Business at Robert Morris University. E-mail: Manna@ @rmu.edu (Corresponding author)

Amanda Weir graduated in May 2011 from Robert Morris University and received a degree in Marketing. While at Robert Morris she was a member of the American Marketing Association, Student Program Board, and the Dining Hall Committee. In the American Marketing Association she participated in the Nintendo case competition which earned her a ticket to the International AMA conference in New Orleans. There she had the chance to give a presentation on Tips for Small Schools. She also is active in her community. Since 2004 she has participated in Light the Night which raises money for the Leukemia and Lymphoma Society. E-mail: ajwst11@ @ail.rmu.edu

\section{REFERENCES}

1. About UPMC. (2011). USEPA Region 3 Sustainable Healthcare Newsletter. . Retrieved February 7, 2011, from UPMC website: http://www.upmc.com/aboutupmc/CommunityCitizenship/greening/Pages/USEPANewsletter.aspx

2. Children's Hospital of Pittsburgh of UPMC. (March 17, 2011). Children's Hospital of Pittsburgh of UPMC Receives Official LEED Certification. Retrieved February 7, 2011, from the Children's Hospital of Pittsburgh's website: http://www.chp.edu/CHP/031711

3. Community Citizenship. (2011). Sustainable Health Care Competition. Retrieved February 7, 2011, from UPMC website: http://www.upmc.com/aboutupmc/CommunityCitizenship/greening/SHIC/Pages/Overview.aspx

4. Community Citizenship. (2011). UPMC's Environmental Initiatives. Retrieved February 7, 2011, from UPMC website: http://www.upmc.com/aboutupmc/CommunityCitizenship/greening/Pages/environmentalinitiatives.aspx 
5. St. Cloud Hospital CentraCare Health System. (2011). Green Initiatives: Environmental Sustainability. Retrieved April 25, 2011, from St. Cloud Hospital's website:

6. http://www.centracare.com/hospitals/sch/green_initiatives.html

7. Supply Chain Management. (2011). Environmentally Preferred Purchasing Process. Retrieved April 10, 2011, from UPMC website:

http://www.upmc.com/Services/supplychainmanagement/Pages/sustainability.aspx

8. U.S. Green Building Council, Inc. (February 2011). LEED 2009 for Healthcare. Retrieved April 10, 2011, from the USGBC website: http://www.usgbc.org/DisplayPage.aspx?CMSPageID=1765 